\title{
High resolution modelling of snow transport in complex terrain using downscaled MM5 wind fields
}

\author{
M. Bernhardt ${ }^{1}$, G. E. Liston ${ }^{2}$, U. Strasser ${ }^{4}$, G. Zängl ${ }^{3}$, and K. Schulz ${ }^{1}$ \\ ${ }^{1}$ Department of Geography, Ludwig-Maximilians-University (LMU), Munich, Germany \\ ${ }^{2}$ Cooperative Institute for Research in the Atmosphere, Colorado State University, Fort Collins, USA \\ ${ }^{3}$ Deutscher Wetterdienst (DWD), Offenbach, Germany \\ ${ }^{4}$ Institut für Geographie und Raumforschung, University of Graz, Graz, Austria
}

Received: 10 June 2008 - Published in The Cryosphere Discuss.: 11 July 2008

Revised: 26 November 2009 - Accepted: 27 January 2010 - Published: 5 February 2010

\begin{abstract}
Snow transport is one of the most dominant processes influencing the snow cover accumulation and ablation in high mountain environments. Hence, the spatial and temporal variability of the snow cover is significantly modified with respective consequences on the total amount of water in the snow pack, on the temporal dynamics of the runoff and on the energy balance of the surface. For the present study we used the snow transport model SnowModel in combination with MM5 (Penn State University - National Center for Atmospheric Research MM5 model) generated wind fields. In a first step the MM5 wind fields were downscaled by using a semi-empirical approach which accounts for the elevation difference of model and real topography, and vegetation. The target resolution of $30 \mathrm{~m}$ corresponds to the resolution of the best available DEM and land cover map of the test site Berchtesgaden National Park. For the numerical modelling, data of six automatic meteorological stations were used, comprising the winter season (September-August) of 2003/04 and 2004/05. In addition we had automatic snow depth measurements and periodic manual measurements of snow courses available for the validation of the results. It could be shown that the model performance of SnowModel could be improved by using downscaled MM5 wind fields for the test site. Furthermore, it was shown that an estimation of snow transport from surrounding areas to glaciers becomes possible by using downscaled MM5 wind fields.
\end{abstract}

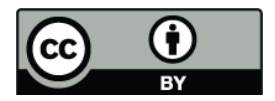

Correspondence to: $\mathrm{M}$. Bernhardt (m.bernhardt@iggf.geo.uni-muenchen.de)

\section{Introduction}

In alpine terrain wind induced snow transport may lead to a significant redistribution of the existing snow cover (Doesken and Judson, 1996; Pomeroy et al., 1998; Balk and Elder, 2000; Doorschot, 2002; Bowling et al., 2004; Bernhardt et al., 2009). As a result snow is transported from windward towards lee regions, into sinks, and at the windward side of taller vegetation or in the lee of e.g. vegetation strips (Pomeroy et al., 1993; Liston and Sturm, 1998; Hiemstra et al., 2003). The resulting heterogeneity of snow cover has effects on the energy balance, the total amount of snow water equivalent (SWE) and the timing and intensity of snowmelt runoff as well as avalanche risk (Liston, 1995; Liston and Sturm, 1998; Liston et al., 2000; Lehning et al., 2006). Furthermore, snow transport may be responsible for an increase in sublimation rates of the snow cover itself as well as of airborne snow particles (Strasser et al., 2008). Many numerical models have been developed over the last years in order to improve the prediction of lateral transport processes within snow hydrological, and/or climate applications (Liston and Sturm, 1998; Déry and Yau, 1999; Essery et al., 1999; Winstral and Marks, 2002; Liston, 2004; Lehning et al., 2006). While a physically based process description is an essential prerequisite, the appropriate reproduction of snow transport processes will largely depend on the representativeness of the meteorological data. The most sensitive parameters concerning the lateral redistribution of snow are wind speed and direction (Essery, 2001; Lehning et al., 2000; Eidsvik et al., 2004; Bernhardt et al., 2009).

Winstral and Marks (2002) outline the difficulties in constraining these two parameters in alpine terrain. Bernhardt

Published by Copernicus Publications on behalf of the European Geosciences Union. 
et al. (2009) utilized a library of pre-generated MM5 wind fields for providing physically derived wind fields as input for SnowModel (Liston and Elder, 2006) and have demonstrated the general functionality of this approach at a gridscale of $200 \mathrm{~m}$. They could show that simulated snow transport was significantly increased when using MM5 wind fields due to elevation and convergence "speed up" effects at the crest regions. While also improving the prediction of erosion and accumulation processes, a precise location of accumulation and erosion zones has been found impossible at least at the $200 \mathrm{~m}$ scale used so far (Bernhardt et al., 2009).

In the following, we extend previous work (Bernhardt et al., 2009) by investigating the prediction of lateral snow transport processes when operating on a much higher spatial resolution of $30 \mathrm{~m}$. This will include the use of a $30 \mathrm{~m}$ digital elevation model (DEM) as a basis for both, the spatial resolution of the snow hydrological modelling and the pregeneration (down-scaling) of MM5 wind fields. We here use SnowModel which has been successfully applied as a land surface model in many snow-hydrological applications for a range of grid sizes (5-200 m) (c.p. Liston and Elder, 2006). In order to further improve SnowModel predictions, a procedure for generating downscaled $30 \mathrm{~m}$ grid MM5 wind fields is introduced to drive fine resolution $(30 \mathrm{~m})$ SnowModel runs. These results are finally evaluated against remotely sensed snow cover maps for the winter season 2003/04 and winter field campaign data of 2004/05. The field campaigns were realized at two sites within the National Park area (Reiteralm and Kühroint, Fig. 1). In addition, the predictive power of the coupled SnowModel-MM5 model is also demonstrated for the snow water equivalent (SWE) dynamics of a small kar glaciers (Blaueis, Fig. 1).

\section{Study area and measurements}

The test site Berchtesgaden National Park is located in the southeast of Germany within the Free State of Bavaria (Fig. 1). The park is centered near $47^{\circ} 36^{\prime} \mathrm{N}, 12^{\circ} 57^{\prime} \mathrm{E}$ and covers an area of $208 \mathrm{~km}^{2}$ with an average altitude of approximately $1000 \mathrm{~m}$ a.s.l. The high alpine area is characterised by rapid changes in elevation (minimum altitude: $501 \mathrm{~m}$ a.s.l., maximum altitude $2713 \mathrm{~m}$ a.s.1.). The vertical difference between the Königssee (603 ma.s.l.) and Watzmann summit ( $2713 \mathrm{~m}$ a.s.1.) is about $2100 \mathrm{~m}$ within a horizontal distance of only $3500 \mathrm{~m}$.

GIS information of vegetation and topography were provided by the National Park authority. The vegetation dataset is based on an interpretation of colour infrared aerial photographs. The DEM used was derived from $20 \mathrm{~m}$ contour lines. Both data sets provide a spatial resolution of $10 \mathrm{~m}$ and were re-sampled to $30 \mathrm{~m}$.

The climate of the National Park area is subject to significant spatial variability, strongly influenced by topography. Small scale local differences are controlled by the general

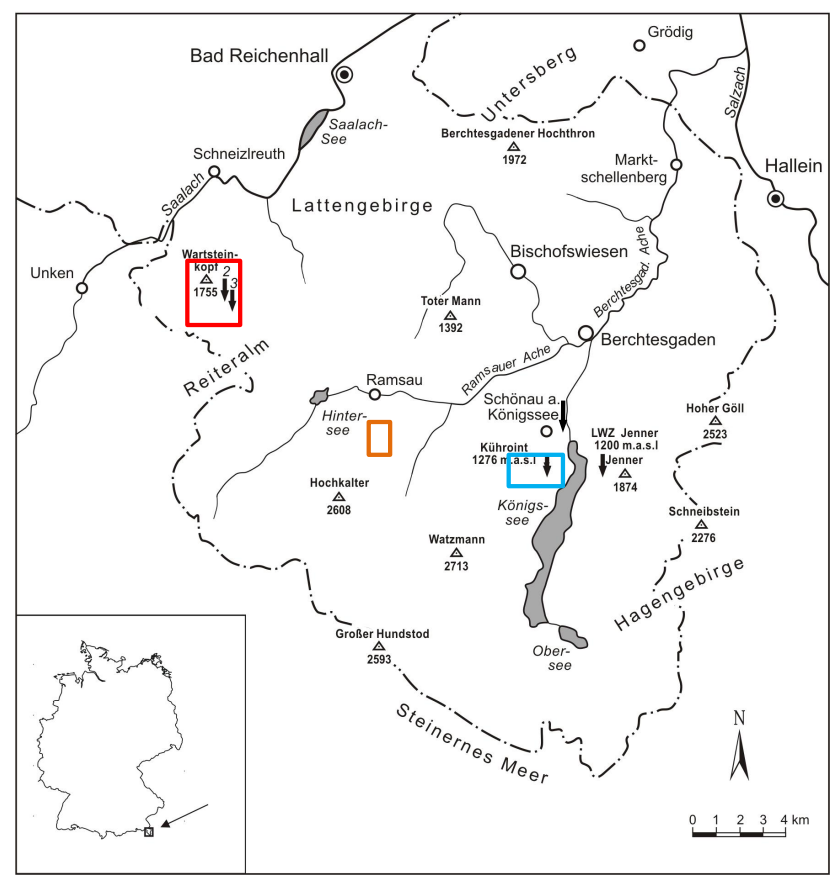

Fig. 1. Test site (Berchtesgaden National Park) (Bayerisches Landesvermessungsamt 1994, modified). The locations of Reiteralm (red) 1, 2 and 3, Schnau, Jenner and Khroint (blue) are marked with arrows. The location of Blaueis glacier is indicated by the brown square.

position within the mountainous landscape, the windward or lee position to the prevailing winds, and solar incidence angles. Meteorological data for the winter season of 2003/04 and 2004/05 were available from six automatic weather stations; Table 1 summarizes their location, measured variables and temporal resolution.

To evaluate the predicted horizontal distribution of snow cover, additional field measurements of snow depth were carried out at two locations: the Reiteralm plateau (Fig. 1) characterized by an extensive flatland with sharp drops around the edges and an average elevation of $1700 \mathrm{~m}$ a.s.1. (minimum and maximum values are $1610 \mathrm{~m}$ and $1753 \mathrm{~m}$ a.s.l., respectively). Mountain pine is the dominant vegetation type, followed by meadows and spruce. The mountain pasture Kühroint is located at approximately $1420 \mathrm{~m}$ a.s.l. in the north-eastern part of the Watzmann massif (Fig. 1), dominated by grassland, clear cut, and coniferous forest. The absolute difference in elevation is small $(70 \mathrm{~m}$ in total). The clear cut and the coniferous forest show undulating terrain with small hills of about five meters in height and an extent of 30 to $40 \mathrm{~m}$. The grassland in contrast is more planar and rises in a westerly direction. Measurements at 11 dates at 30 staff gauges were taken between February and April 2005. Model results are also discussed on the basis of Blaueis glacier which is located at the northern part of Hochkalter massif (brown rectangle in Fig. 1). Blaueis is a small kar glacier and 
Table 1. Meteorological stations within the Berchtesgaden National Park. The abbreviations, geographical coordinates, elevation, meteorological recordings and temporal resolution are shown: wind speed (WS), wind direction (WD), temperature $(T)$, humidity $(H)$, snow height $(\mathrm{SH})$, global radiation $(\mathrm{GR})$, and precipitation $(P)$.

\begin{tabular}{llllll}
\hline Station & $\begin{array}{l}\text { Elev } \\
\text { (a.s.1.) }\end{array}$ & $\begin{array}{l}\text { Long } \\
(\text { deg/east) }\end{array}$ & $\begin{array}{l}\text { Lat } \\
(\mathrm{deg} / \text { north) }\end{array}$ & $\begin{array}{l}\text { Temporal } \\
\text { resolution }\end{array}$ & $\begin{array}{l}\text { Measured } \\
\text { Parameters }\end{array}$ \\
\hline Jenner I & $1200 \mathrm{~m}$ & 13.01926 & 47.58648 & $10 \mathrm{~min}$ & $T, H, \mathrm{SH}$ \\
Kühroint & $1407 \mathrm{~m}$ & 12.95945 & 47.57142 & $10 \mathrm{~min}$ & $T, H, \mathrm{GR}, \mathrm{WS}, \mathrm{WD}, P, \mathrm{SH}$ \\
Reiter Alm I & $1755 \mathrm{~m}$ & 12.80532 & 47.65132 & $10 \mathrm{~min}$ & $\mathrm{WS}, \mathrm{WD}$ \\
Reiter Alm II & $1670 \mathrm{~m}$ & 12.80984 & 47.64949 & $10 \mathrm{~min}$ & $T, H, \mathrm{SH}$ \\
Reiter Alm III & $1615 \mathrm{~m}$ & 12.81133 & 47.64720 & $10 \mathrm{~min}$ & $T, H, \mathrm{GR}, P, \mathrm{SH}$ \\
Schönau & $617 \mathrm{~m}$ & 12.98332 & 47.60941 & $10 \mathrm{~min}$ & $T, H, \mathrm{GR}, \mathrm{WS}, \mathrm{WD}, P$ \\
\hline
\end{tabular}

the northernmost glacier within the European Alps. The area of the glacier was 11 ha in 2006 and the total extent in elevation was about $400 \mathrm{~m}$ (from $1910 \mathrm{~m}$ a.s.l. up to $2385 \mathrm{~m}$ a.s.l.).

\section{Model}

SnowModel (Liston and Elder, 2006) was used for the calculation of the snow cover development and for the description of snow transport processes in combination with the Penn State University - National Center for Atmospheric Research MM5 model (MM5), version 3.3 (Grell et al., 1995). Wind induced snow transport is described via SnowTran-3D (Liston and Sturm, 1998) which is implemented within SnowModel. SnowTran3D is based on a mass balance equation describing the temporal variation of snow depth at any grid cell:

$$
\frac{\partial \zeta}{\partial t}=\frac{1}{\rho_{\mathrm{s}}}\left[\rho_{\mathrm{w}} P-\left(\frac{\partial Q_{\mathrm{s}}}{\partial x}+\frac{\partial Q_{\mathrm{t}}}{\partial x}+\frac{\partial Q_{\mathrm{s}}}{\partial y}+\frac{\partial Q_{\mathrm{t}}}{\partial y}\right)-Q_{\mathrm{v}}\right]
$$

with $Q_{\mathrm{s}}=$ horizontal mass-transport rates of saltation $\left(\mathrm{kg} \mathrm{m}^{-1} \mathrm{~s}^{-1}\right), Q_{\mathrm{t}}=$ horizontal mass-transport rates of turbulent suspended snow $\left(\mathrm{kg} \mathrm{m}^{-1} \mathrm{~s}^{-1}\right), Q_{\mathrm{v}}=$ sublimation of transported snow $\left(\mathrm{kg} \mathrm{m}^{-2} \mathrm{~s}^{-1}\right), P=$ water equivalent precipitation rate $\left(\mathrm{m} \mathrm{s}^{-1}\right), \zeta=$ snow depth $(\mathrm{m}), t=$ time $(\mathrm{s}), x$ and $y=$ horizontal coordinates $(\mathrm{m}), \rho_{\mathrm{s}}=$ snow density $\left(\mathrm{kg} \mathrm{m}^{-3}\right)$, and $\rho_{\mathrm{w}}=$ water density $\left(\mathrm{kg} \mathrm{m}^{-3}\right)$.

The model predicts the spatio-temporal dynamics of distributed snow depths as controlled by the horizontal mass transport rates of saltation and turbulent suspended snow, the sublimation losses of transported particles and the water equivalent precipitation rate. A detailed description of the snow density development and the other process formulations is given by Liston and Elder (2006) and Liston and Sturm (1998). SnowTran3D has proven its applicability for a wide range of environments from Arctic plains (Liston and Sturm, 1998; Liston and Sturm, 2002) to mountainous terrain (Greene et al., 1999; Liston et al., 2000; Prasad et al., 2001; Hiemstra et al., 2003, 2006; Hasholt et al., 2003; Bruland et al., 2004; Bernhardt et al., 2009).
The quasi-physically-based meteorological distribution model MicroMet (Liston and Elder, 2006) - also implemented in SnowModel - has been used for the spatial interpolation of meteorological measurements including air temperature, incoming longwave radiation, incoming solar radiation, precipitation, relative humidity, surface pressure, wind direction, and wind speed. The spatial distribution of wind speed and direction measurements follows the approach of Ryan (1977) and Liston and Sturm (1998). A comprehensive description of the MicroMet interpolation schemes can be found in Liston and Elder (2006). While a former study of Bernhardt et al. (2009) has shown the limitations of using MicroMet interpolated wind fields from local stations, a more physically based approach using MM5 generated wind fields is tested here instead.

An operational coupling between atmospheric model and snow transport model was not pursued because of the high computational costs of the atmospheric model. Thus, a library of MM5 wind fields was produced in advance. The library contains representative wind fields for the most common wind situations at the test site (Bernhardt et al., 2009) and was linked to the snow transport model via operational German weather service Lokalmodell (Adrian and Frühwald, 2002) results. This becomes possible because of the comparability of a MM5 model layer with one of the Lokalmodell model layers. To link the wind field library to the snow model all of the predicted MM5 wind fields were characterised by information available from the Lokalmodell. This enable an easy detection of the MM5 wind field which is closest to the real climatic wind conditions at any Lokalmodell time step $(1 \mathrm{~h})$ The wind field library was produced by an adapted version of MM5 allowing for a spatial resolution of $200 \mathrm{~m}$. However, due to numerical stability requirements of MM5 the $200 \mathrm{~m} \mathrm{DEM}$ had to be smoothed at some locations. An extensive description of the generation of the wind field library can be found in Bernhardt et al. (2009). Also, in order to run the SnowModel at a high spatial resolution of $30 \mathrm{~m}$, a downscaling procedure had to be developed for producing wind fields at a corresponding $(30 \mathrm{~m})$ grid size. 
A novel method addressing both issues - the smoothing and an appropriate downscaling algorithm - will be presented in the next section, before applying the coupled SnowModel-MM5 model (using a temporal resolution of $1 \mathrm{~h}$ ) over a domain of about $400 \mathrm{~km}^{2}$ covering the total area of the Berchtesgaden National Park.

\section{Downscaling of MM5 wind fields}

\subsection{The downscaling procedure}

The required smoothing of the MM5 used $200 \mathrm{mDEM}$ as described in Sect. 3 leads to a shift of the apexes and minima when compared to the high resolution $30 \mathrm{~m}$ DEM provided by the Nationalpark. These deviations are especially obvious at very exposed areas like Reiteralm (Fig. 2), Watzmann, or Hochkalter. In the case of the Reiteralm the crest of Wartsteinkopf still appears, but as can be seen in Fig. 2 is altered in position and orientation.

Spatial offsets can also be detected when analyzing the wind fields themselves. The topographically caused convergence of the airstream and the resulting acceleration of the air masses at the mountains crests are shifted into the faces of the respective massifs when using the $30 \mathrm{~m}$ DEM. For the geometric correction of the $200 \mathrm{~m}$ resolution smoothed DEM and corresponding MM5 wind fields, a polynomial re-sampling approach (Eqs. 2 and 3) with designated control points was applied, using the high resolution Nationalpark $30 \mathrm{~m}$ DEM as a reference map:

$R^{\prime}=a 1 \cdot R^{2}+a 2 * C^{2}+a 3 \cdot R+a 4 \cdot C+a 5 \cdot R \cdot C+a 6$

$C^{\prime}=b 1 \cdot R^{2}+b 2 \cdot C^{2}+b 3 \cdot R+b 4 \cdot C+b 5 \cdot R \cdot C+b 6$

with $R^{\prime}=$ new row coordinate, $C^{\prime}$ is new column coordinate, $R=$ old row coordinate, $C=$ old column coordinate, $a 1-6$ and $b 1-6=$ parameters defined over the control points.

The control points are used to generate a (polynomial) transformation that is able to shift the grid elements of the $200 \mathrm{~m} \mathrm{DEM}$ to the spatially correct location defined by the original $30 \mathrm{~m}$ DEM. At least six control points are needed for estimating the coefficients $a 1-a 6$ and $b 1-b 6$, which are then also used for correcting all MM5 wind fields.

In the next step, the spatial resolution of the MM5 wind fields was reduced to $30 \mathrm{~m}$ by eliminating the coarse grid structure (as evident in Fig. 3a). This was done with a statistical smoothing algorithm and in order to prevent SnowModel predictions from artefacts (edge effects) of the original $200 \mathrm{~m}$ resolution. A radial basis function (RBF) (Eq. 4) was used for smoothing of the wind fields while conserving the total amount of energy within each wind field:

$$
\begin{aligned}
\phi(r) & =-\sum_{n=1}^{\infty} \frac{(-1)^{n}(\sigma \cdot r)^{2 n}}{n ! n}=\ln (\sigma \cdot r / 2)^{2}+E_{1}(\sigma \cdot r / 2)^{2} \\
& +C_{\mathrm{E}}
\end{aligned}
$$
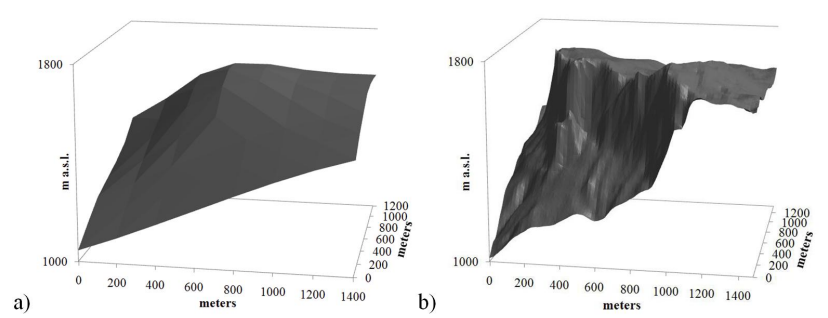

Fig. 2. Test site Reiteralm within the smoothed 200 m MM5 DEM (a), and with a original $30 \mathrm{~m}$ resolution (b).

with $\phi(r)=$ Radial basis function, $r=$ the Euclidean distance $\left(r=\left\|s_{i}-s_{0}\right\|\right)$ between the prediction location $s_{0}$ and each data location $s_{i}, \sigma=$ the smoothing parameter, $E_{1}=$ exponential integral function, and $C_{\mathrm{E}}=$ Euler constant.

$\mathrm{RBF}$ is an exact interpolation technique forcing the new surface through local measurement points. As a result, any $200 \mathrm{~m}$ grid element has an identical mean when compared to the average of corresponding newly generated $30 \mathrm{~m}$ grid cells.

As mentioned before, the minima and maxima elevation values have been smoothed within the MM5 200 m DEM. A reduction of elevation and slope angles results in damped modelled speed up effects at the crest regions. To address this effect, the elevation difference between any $30 \mathrm{~m}$ pixel and the respective $200 \mathrm{~m}$ pixel was calculated. Subsequently, the elevation gradient of wind speed was calculated for each modelled wind field. It became obvious that there are two distinguishable elevation gradients within the datasets. There is one gradient for the interval from 500 to $1800 \mathrm{~m}$ a.s.l. and another for 1800 to $2700 \mathrm{~m}$ a.s.l. This separation was necessary as the gradient above $1800 \mathrm{~m}$ a.s.l. was considerably steeper compared to lower elevation intervals. As a result, this analysis provides a value for the increase of wind speed per meter elevation for the two intervals. In a subsequent step, these gradients were combined with the elevation difference of the two DEMs. Hence, higher wind speeds were generated at locations with positive divergences, and reduced values were computed at locations where MM5 $200 \mathrm{~m}$ DEM elevation values are higher than the ones of the $30 \mathrm{~m}$ DEM. Therefore, the resulting correction file contains a positive or negative correction value for all $30 \mathrm{~m}$ pixels. These values were added to the geometrically corrected and smoothed MM5 wind field. Due to the relatively coarse resolution of $200 \mathrm{~m}$ most of the small scale sinks, hills and vegetation information of the $30 \mathrm{mDEM}$ were not considered during the MM5 modelling procedure thus having no influence on the generated wind fields. A subsequent consideration of subscale information was implemented by using methods introduced by Ryan (1977) and Liston and Sturm (1998) for a modification of wind speed and direction. Figure 3 demonstrates these steps showing largely improved details in the final version of the downscaled wind fields. In particular 

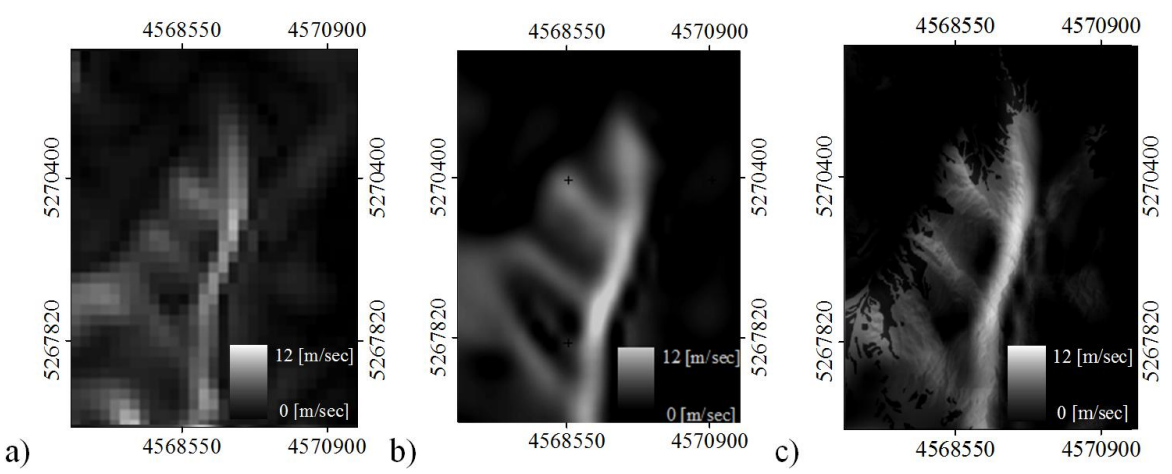

Fig. 3. (a) Original $200 \mathrm{~m}$ MM5 data, (b) smoothed MM5 wind field with a resolution of $30 \mathrm{~m}$, (c) final $30 \mathrm{~m}$ MM5 wind field.

the impact of vegetation leads to very small wind speeds in forested regions. This effect becomes obvious in Fig. 3c and can be identified through sharp black edges.

\subsection{Validation of downscaled MM5 wind fields}

The correlation between measured and modelled daily wind speeds was greatly improved by the downscaling procedure. The original modelled data correlated with an $r^{2}$ of 0.41 to the measurements while the downscaled set produced an $r^{2}$ of 0.62 for the season 2003/04 (Fig. 4a, b).

The weak correlation $\left(r^{2}=0.21\right)$ of hourly measurements is caused by the general omittance of local and temporary phenomena (like cooling or heating of some areas etc.) by the MM5 model, since model runs were initiated with the intention of reaching steady state conditions for the wind fields under a certain synoptic inflow. The rationale behind this strategy is driven by the assumption that high wind speeds that are generating remarkable snow transport events are predominantly controlled by synoptic inflow rather than local and micrometeorological effects. Summarizing, the determination of the current wind field depends on the synoptic situation which changes less frequently compared to local conditions and low correlation of hourly results are therefore in line with expectations.

While providing considerably better local wind speed predictions, MM5 generated wind directions are a fundamental improvement in comparison to standard interpolation procedures as can be seen for the Reiteralm in Fig. 5, when being evaluated against local measurements. The accuracy (maximum deviation) of the predicted wind directions falls within $10 \%$ for about $50 \%$ of all measurements (September 2003August 2004) and within 20\% for about 75\% (Fig. 5b).

\section{Snow transport modelling results}

In the following, the performance of the combined SnowModel - MM5 model is analyzed when predicting horizontal snow transport processes at two test sites, Reiteralm and
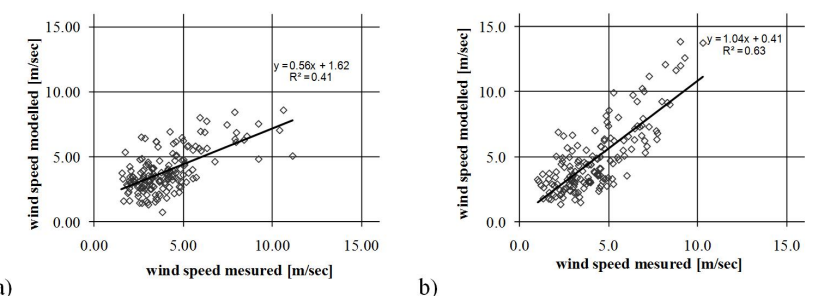

Fig. 4. (a) Correlation between MM5 results and station recordings before the downscaling procedure (Reiteralm I, daily resolution). (b) Correlation between MM5 results and station recordings after the downscaling procedure. The regression lines are highlighted in black.
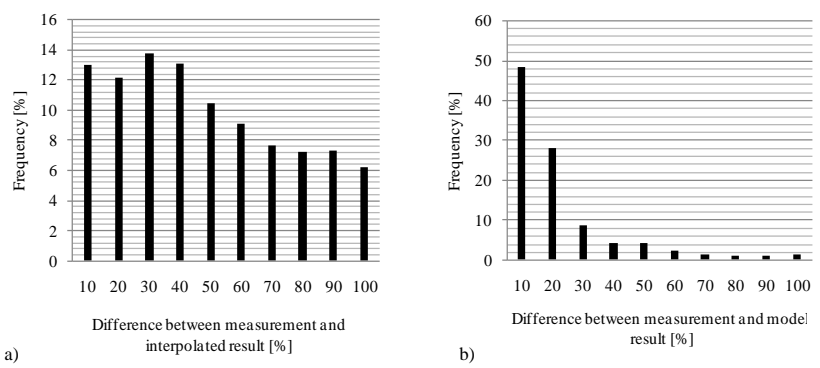

Fig. 5. (a) Results of interpolated and measured wind directions. The figure shows that $13 \%$ of the interpolation results showing a deviation to the measurements which is less than $10 \%, 12 \%$ are less than $20 \%$ and so on. (b) Results of modeled 30 m MM5 data and wind direction measurements. The figure shows that $48 \%$ of the model results showing a deviation to the measurements which is less than $10 \%, 28 \%$ are less than $20 \%$ and so on. A difference of $100 \%$ means that the interpolated wind speed is opposite to the measured one $\left(180^{\circ}\right)$.

Kühroint (Sects. 5.1 and 5.2). Also, a comparison between a $200 \mathrm{~m}$ and a $30 \mathrm{~m}$ grid application will allow scale effects to be quantified (Sect. 5.3). A case study at the Blaueis glacier (Sect. 5.4) and a spatial validation exercise using Landsat remote sensing images (Sect. 5.5) will demonstrate 
the applicability of the model to a larger range of scales and conditions.

The available satellite images are from April and May 2004 while the field campaign was realized from January 2005 onward. Satellite images of 2005 were not available because the target region was cloud covered for all available dates. Hence, SnowModel runs were performed for the winter season 2003/04 and 2004/05 with a temporal resolution of one hour and a spatial resolution of $30 \mathrm{~m}$. The required input parameters, precipitation, humidity, radiation, wind speed, wind direction, air pressure and air temperature were delivered by six meteorological stations (Table 1). The original $10 \mathrm{~min}$ data was averaged to hourly values for this study. Reiteralm has an area of about $2 \mathrm{~km}^{2}$ and is equipped with 3 meteorological stations. Two of them were installed for observing snow transport activities from the higher situated meteorological station 2, to station 3 (Fig. 1). At Kühroint, mainly sheltered from the wind impact, the focus was on correctly reproducing "no transport" conditions.

The parameterization of vegetation classes, decisively controlling the snow holding capacity, was adopted from Liston and Sturm (1998) for the first model run at Reiteralm. After that, a vegetation type "sporadic trees" was created for areas with sparse canopy stands.

\subsection{Reiteralm}

The SnowModel predicted snow depths were generally overestimated at the upper part of Reiteralm and underestimated at the lower parts (see Fig. 6, symbols). A comparison of model and field campaign results reveals that differences between the measurements at the sample points could be reproduced by the model to some degree, but the modelled variability is generally too small (Table 2).

Table 2 shows the standard deviations (SD) of all measurements per date in comparison to SnowModel predicted values. It is obvious that SDs between measurement points are significantly higher than corresponding SnowModel results. Furthermore, the temporal variations of the measured snow depths are also higher, than those of modelled values. The differences within the model results are approximately similar for the first seven dates and only slightly smaller for the last two dates. Experiences of the Avalanche Warning Service of Bavaria, observing this site for over 10 years, indicate that considerable amounts of snow are blown from the upper (characterized by sample points 1-8, Fig. 6) to the lower part of the site (sample points 14 and 15, Fig. 6).

This experience is confirmed by the snow depth measurements of the automatic meteorological stations Reiteralm II and III but could not be fully reproduced by SnowModel. Horizontal transport processes were underestimated during the first model run using the vegetation class parameterisation of Liston and Sturm (1998), thus a vegetation type "sporadic tree" was created for areas with sparse canopy stands by reducing the snow holding capacity of "deciduous forest"

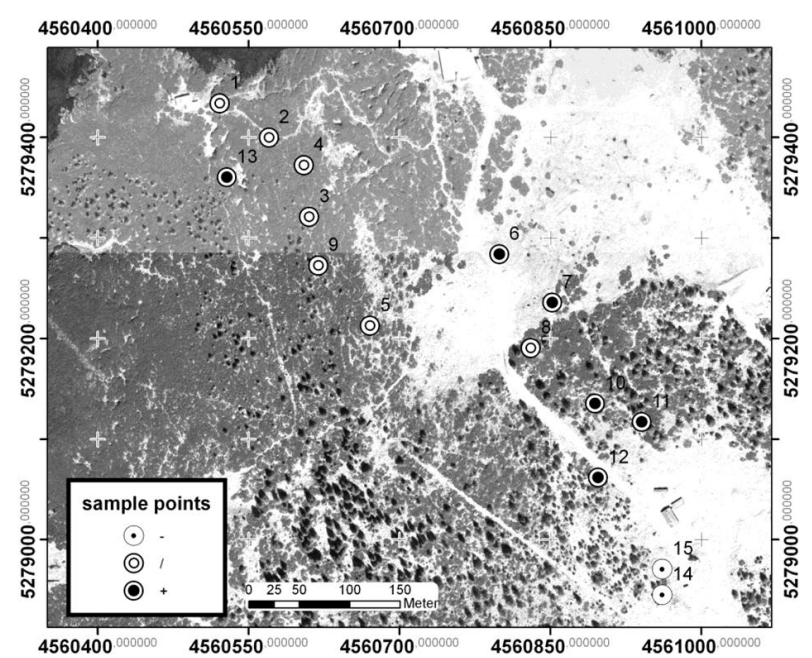

Fig. 6. Test site Reiteralm: the points indicate the position of the snow gauges. White points with a large black dot in the middle indicate that the modelled snow depth of the winter season 2004/05 was in average more than $10 \%$ higher than the measured one, whereas white points with a small black point indicate that the modelled snow depth was in average more than $10 \%$ below of the measurements. White points with a black ring standing for measuring points were the model results are within these thresholds.

to $2 \mathrm{~m}$. By adding the new vegetation type and MM5 wind fields the model results could be improved at the upper part of the Reiteralm (c.p. Fig. 7a), but there were no changes at the lower part (c.p. Fig. 7b, c). When comparing model results using modelled MM5 versus standard interpolated wind fields, differences could be only found at the upper stations (Fig. 7a). Differences at other stations (close to or within the forest) were negligible.

\subsection{Kühroint}

The comparison of predicted and measured snow depths at Kühroint shows acceptable results. The model is within $10 \%$ error at seven of 15 sample points. It underestimates the snow depth by more than $10 \%$ in average for six points and overestimates the snow depth by more than $10 \%$ in average for two points (Fig. 8). The distribution of the sample points is visualized in Fig. 8. It can be seen that the snow depth is especially underestimated by SnowModel for the sample points in the north eastern part, whereas the results at the centre and at the western parts fit very well to the measurements. The results summarized in Table 3 correspond to findings at test site Reiteralm. The SD's of the measurements are again higher than those of the model results, lying in between $31 \mathrm{~mm}$ and $43 \mathrm{~mm}$ (Table 3). The predicted standard deviations for the SnowModel results are especially small at the first five dates (around $4 \mathrm{~mm}$ ) and reach up to $17 \mathrm{~mm}$ for the succeeding dates. 
Table 2. Standard deviations of snow depth measurements and of the respective model results for the observation dates (Reiteralm).

\begin{tabular}{rrrrrrrrrr}
\hline & 08.02 .04 & 15.02 .04 & 23.02 .04 & 02.03 .04 & 10.03 .04 & 14.03 .04 & 23.03 .04 & 30.03 .04 & 05.04 .04 \\
\hline Measured & $43 \mathrm{~mm}$ & $41 \mathrm{~mm}$ & $35 \mathrm{~mm}$ & $39 \mathrm{~mm}$ & $54 \mathrm{~mm}$ & $53 \mathrm{~mm}$ & $38 \mathrm{~mm}$ & $37 \mathrm{~mm}$ & $39 \mathrm{~mm}$ \\
Modelled & $19 \mathrm{~mm}$ & $19 \mathrm{~mm}$ & $21 \mathrm{~mm}$ & $20 \mathrm{~mm}$ & $24 \mathrm{~mm}$ & $23 \mathrm{~mm}$ & $17 \mathrm{~mm}$ & $14 \mathrm{~mm}$ & $12 \mathrm{~mm}$ \\
\hline
\end{tabular}

Table 3. Standard deviations of the snow depth measurements and of the respective model 1 results for the observation dates (Kühroint).

\begin{tabular}{lrrrrr}
\hline & 08.02 .04 & 15.02 .04 & 22.02 .04 & 02.03 .04 & 08.03 .04 \\
\hline $\begin{array}{l}\text { Measured } \\
\text { Modelled }\end{array}$ & $37 \mathrm{~mm}$ & $36 \mathrm{~mm}$ & $31 \mathrm{~mm}$ & $32 \mathrm{~mm}$ & $40 \mathrm{~mm}$ \\
& 15.03 .04 & 22.03 .04 & 29.03 .04 & 12.04 .04 & 19.04 .04 \\
\hline Measured & $37 \mathrm{~mm}$ & $33 \mathrm{~mm}$ & $36 \mathrm{~mm}$ & $43 \mathrm{~mm}$ & $36 \mathrm{~mm}$ \\
Modelled & $17 \mathrm{~mm}$ & $15 \mathrm{~mm}$ & $13 \mathrm{~mm}$ & $16 \mathrm{~mm}$ & $14 \mathrm{~mm}$ \\
\hline
\end{tabular}

point 4

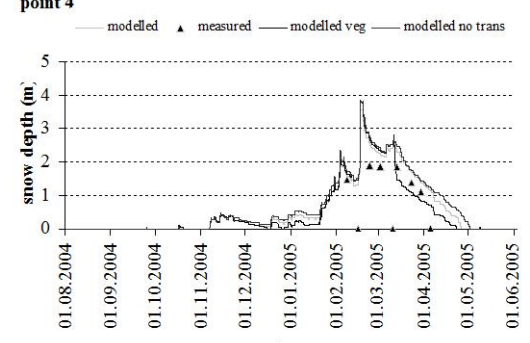

a)

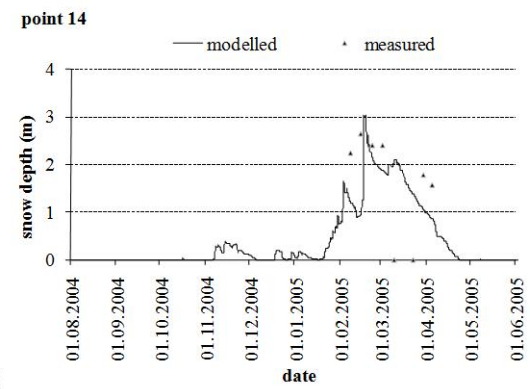

c) b)

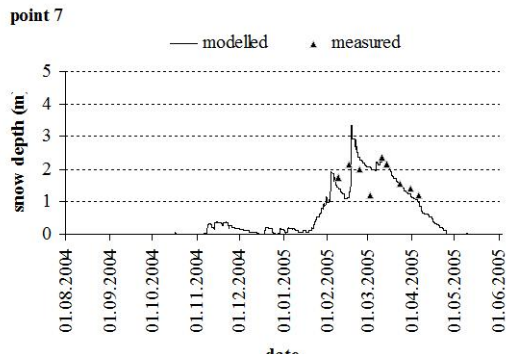

dat

Fig. 7. SnowModel predicted versus measured snow depths at three representative locations at Reiteralm. (a) is representative for the upper part of Reiteralm. It shows the difference between the original SnowModel MM5 runs and the runs which used the vegetation class sporadic trees instead of the original parameterisation (characterized by "modelled veg"). (b) A representative result for the central region and (c) for the lower part (c.p. Fig. 6). The introduction of sporadic trees has not modified the results of (b) and (c).

Figure 9 shows three sample points at Kühroint. Point N) is located at the edge of the forest at the northern part of Kühroint; point F) is located at the clear cut area, and point $\mathrm{K}$ ) can be found on the meadows in the western part of the area. The three points represent the range of model results of snow depth versus observational data: maximum overestimation $\mathrm{N}$ ), best fit $\mathrm{K}$ ) and maximum underestimation $\mathrm{F}$ ).

\subsection{Comparison of $200 \mathrm{~m}$ and $30 \mathrm{~m}$ results}

As already outlined in Bernhardt et al. (2009), the increase in wind speed with elevation and the differentiation between windward and leeward areas is more distinctive when using MM5 wind fields instead of interpolation results from local measurements. If SnowModel is driven (over the complete model domain) by original MM5 derived wind fields at the $200 \mathrm{~m}$ scale, only $84 \%$ of the modelled variance within the 


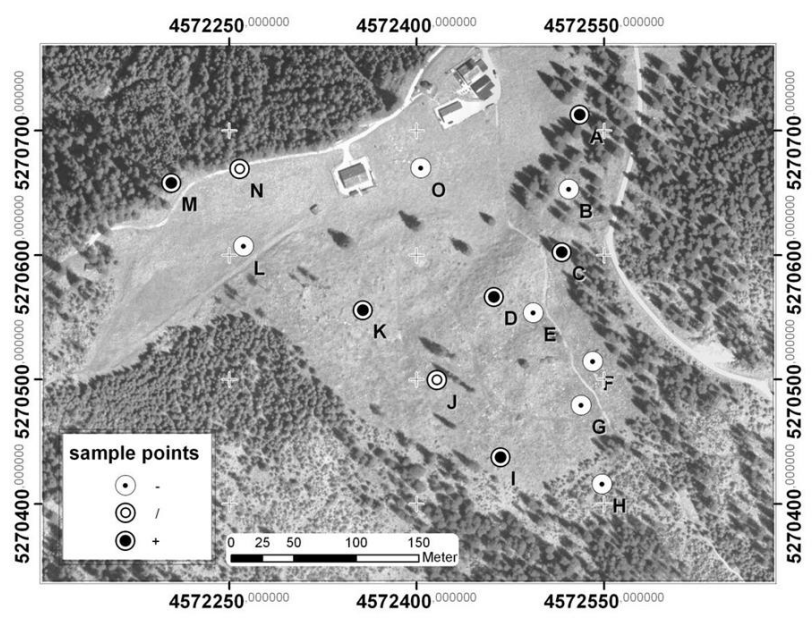

Fig. 8. The points indicating the position of the snow gauges. White points with a large black dot in the middle indicate that the modelled snow depth of the winter season 2004/05 was in average more than $10 \%$ higher than the measured one, whereas white points with a small black point indicate that the modelled snow depth was in average more than $10 \%$ below of the measurements. White points with a black ring standing for measuring points were the model results are within these thresholds.

SWE distribution can be related to altitudinal effects. The remaining variance is due to aspect. Using interpolated wind fields from local measurements at this scale instead, the percentage related to altitude has increased to $96 \%$, leaving the contribution of aspects negligible (Fig. 10).

The $30 \mathrm{~m}$ predictions of SWE are considerably different when compared to $200 \mathrm{~m}$ results. Other than in the $200 \mathrm{~m}$ model resolution runs, the statistical correlation of elevation and SWE is approximately the same for results with and without MM5 wind fields (MM5: $r^{2}=0.93$ and MicroMet: $\left.r^{2}=0.94\right)$. Figure 10 shows that there is no significant correlation between SWE distribution and aspect. The rates of individual snow transport components as illustrated in Fig. 12 on the other hand shows a similar distribution as compared to the $200 \mathrm{~m}$ SnowModel/MM5 runs. Considerable transport rates can be observed at crest regions but the spatial extent of the affected areas is smaller for the $30 \mathrm{~m}$ results and does not therefore significantly influence the absolute SWE distribution of the area shown in Fig. 11. When comparing to the $200 \mathrm{~m}$ MM5 results, the $30 \mathrm{~m}$ MM5 transport pattern is more heterogeneous and does not show the clear transport tendency from west to east seen in Fig. 12. For example, transport processes with a south to north component can now be observed at the small crests at the west side of Hochkalter or Watzmann massif which stretch from west to east.

The effect of the sublimation processes within the $200 \mathrm{~m}$ and $30 \mathrm{~m}$ results can be observed in Fig. 10e and f. The maximum modelled sublimation rates are slightly higher than those of the $200 \mathrm{~m}$ MM5 runs $(920 \mathrm{~mm}$ to $860 \mathrm{~mm}$ ) but the total amount of sublimation for the whole area is significantly smaller ( $0.5 \mathrm{~mm}$ to $12 \mathrm{~mm}$ per $30 \mathrm{~m}$ grid cell in average) This is due to the fact that areas of high sublimation rates are again limited to the crest regions having a smaller spatial extent in the high resolution DEM. Furthermore, the intensity of the saltation and suspension process is higher within the $30 \mathrm{~m}$ runs (Fig. $12 \mathrm{~b}$ and $\mathrm{d}$ ).

\subsection{Case study "Blaueis" glacier}

The results achieved for Blaueis glacier have shown that the amount of transported SWE considerably depends on the selected model scale and wind simulation method. Principally, it can be stated that the use of SnowModel does not lead to any transport rates from and to the glacier if interpolated wind fields are used. This finding is independent of the used scale. When MM5 wind fields are used on the other hand, significant transport processes can be observed. The SnowModel $30 \mathrm{~m}$ runs in combination with MM5 produce a maximum SWE gain per pixel of $2140 \mathrm{~mm}$ SWE. The average contribution of windblown snow over the total glacier area is $220 \mathrm{~mm}$ SWE. The additional amount of SWE corresponds to $12 \%$ of the total precipitation $(1850 \mathrm{~mm})$ and to $23 \%$ of the snowy precipitation $(950 \mathrm{~mm})$ within the observed period (03/04) (Fig. 13a).

The $200 \mathrm{~m}$ runs in contrast produce considerably different results. The maximum gain per pixel is greatly reduced (740 mm SWE) and the total average contribution is only $4 \mathrm{~mm}$ SWE (Fig. 13b). This can be explained by a scale dependent shift - as presented for Reiteralm (Fig. 2a and b) generating an erosion zone of the glacier located in the crest region of Hochkalter within in the $200 \mathrm{~m}$ DEM. Hence, erosion prevails and the SWE is reduced compared to the $30 \mathrm{~m}$ runs. Figures 13a and $\mathrm{b}$ show the wind induced gain and loss of SWE for the Blaueis glacier ( $30 \mathrm{~m}$ vs. $200 \mathrm{~m}$ resolution, again), illustrating the problem of an accurate estimation of the location of the accumulation and erosion zones at coarser scales (see Liston, 2004).

\subsection{Spatial validation of the $30 \mathrm{~m}$ SnowModel-MM5 results}

The $30 \mathrm{~m}$ SnowModel results are spatially evaluated on the basis of remotely sensed data. Model predictions correspond to the extent and support (Blöschl and Sivapalan, 1995) of Landsat 7 ETM+ images allowing a direct comparison.

As a first step, the extent of the modelled snow cover was compared to classified Landsat ETM+ images. The Normalized Difference Snow Index (NDSI, Hall et al., 1995) was used for the classification. The following results are valid for SnowModel runs with and without MM5 wind fields which is due to the fact that both runs are identical with respect to the snow line. $86 \%$ of the model grid points are in agreement with the remotely sensed snow map for 28 April, 2004 and $88 \%$ for 30 May, 2004. 5\% of the pixels are classified as snow, but do not show a snow cover within the predictions on 

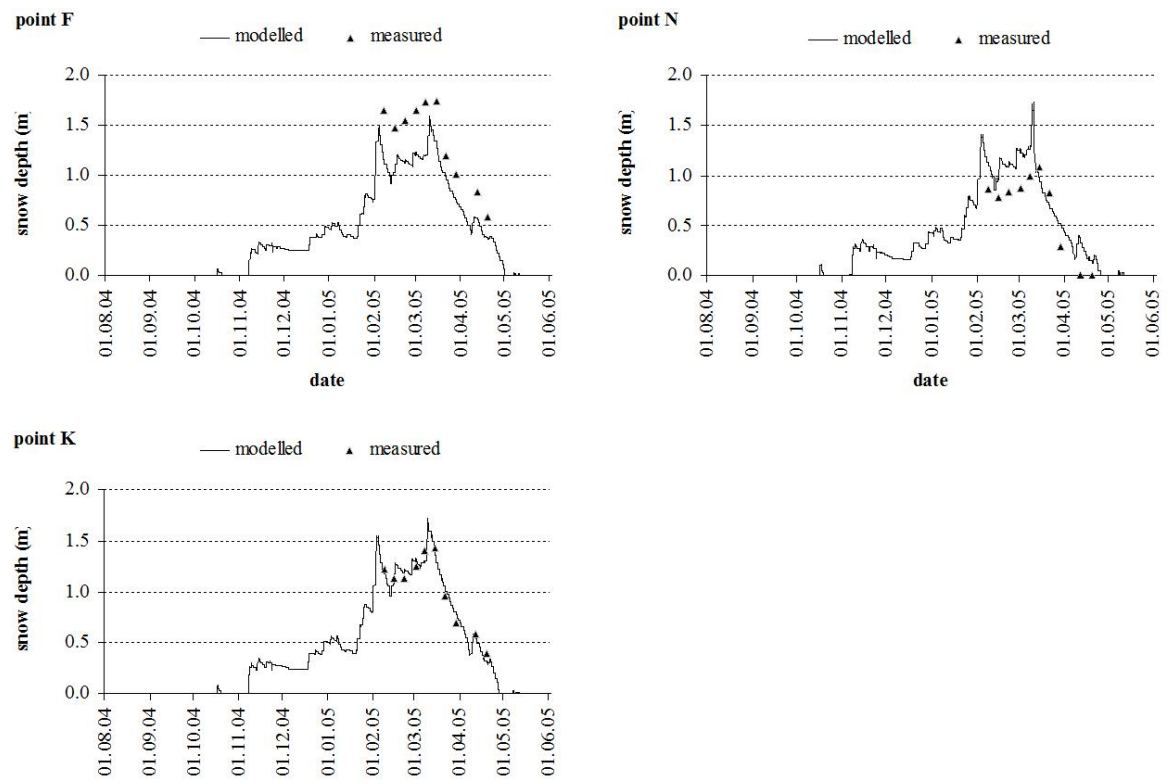

Fig. 9. SnowModel predicted versus measured snow depths at three representative locations at Kühroint covering the range of model results of snow depth versus observational data: maximum overestimation $\mathrm{N}$ ), best fit $\mathrm{K}$ ) and maximum underestimation $\mathrm{F}$ ).

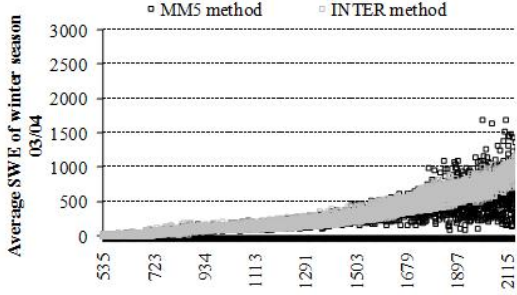

a)

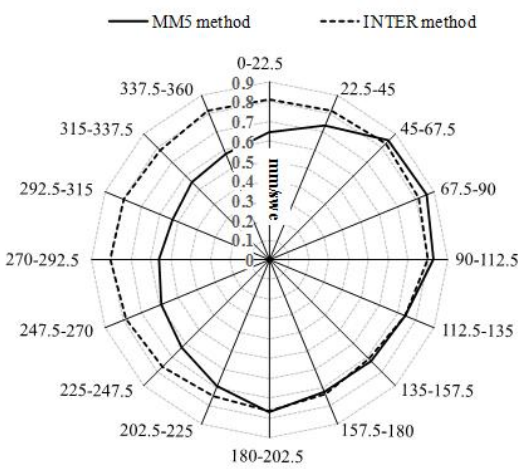

c)

Fig. 10. SnowModel predictions over the winter season 2003/04 at different spatial scales comparing MM5 (MM5 method) generated and interpolated wind (INTER method) fields. (a) SWE [m] - elevation dependency; (b) SWE - aspect dependency for the total elevation interval; (c) SWE - aspect dependency for elevations higher than $1800 \mathrm{~m}$ a.s.l.; (d) SWE - aspect dependency for elevations higher than $2200 \mathrm{~m}$ a.s.l. SWE are the average values for the modelled time period. The different volumes under the curves are due to higher sublimation losses within the MM5 runs. 

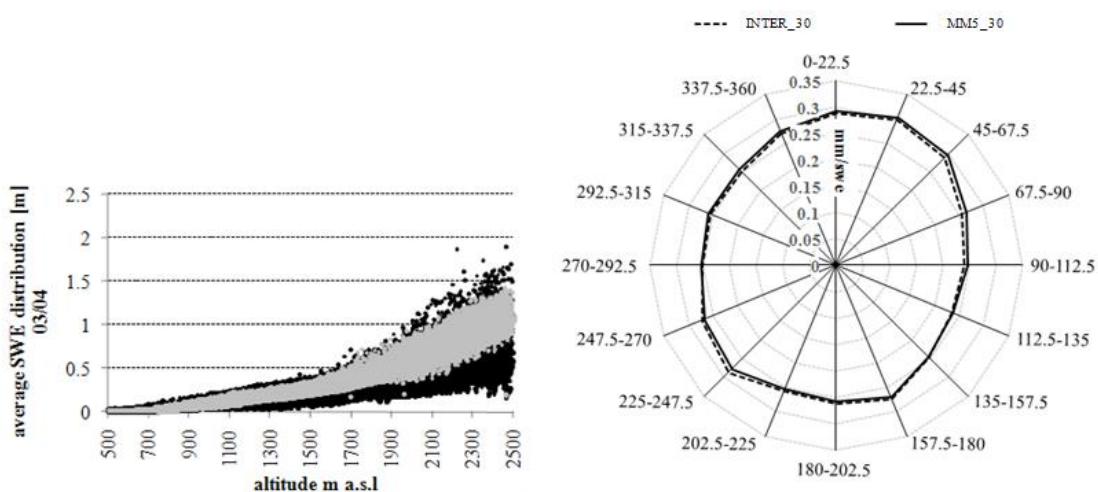

a)

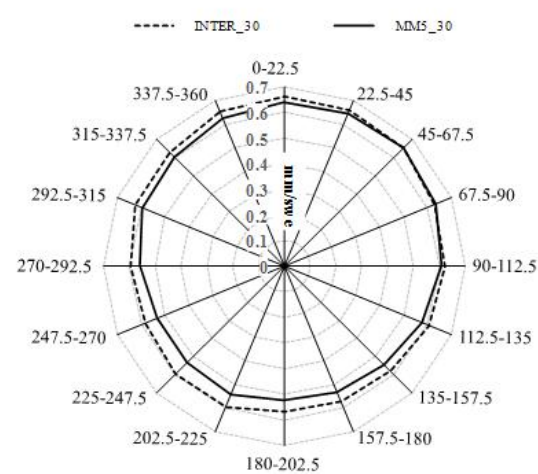

c) b)

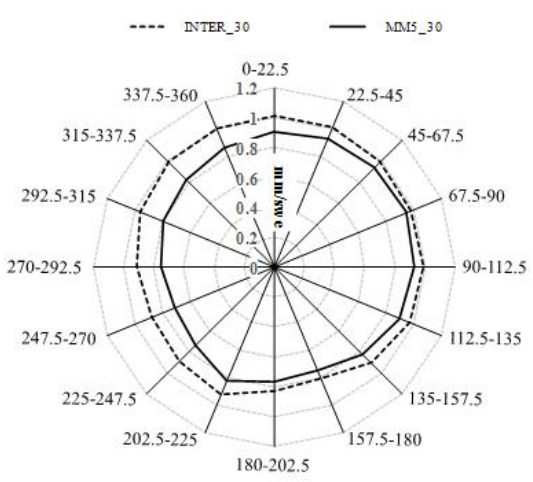

d)

Fig. 11. SnowModel predictions over the winter season 2003/04 comparing $30 \mathrm{~m}$ MM5 generated (MM5 method) and interpolated (INTER method) wind fields. Mean modeled SWE distribution for (a) the total area, (b) areas above $1800 \mathrm{~m}$ a.s.l. and (c) areas above $2200 \mathrm{~m}$ a.s.1. The different volumes under the curves are due to higher sublimation losses within the MM5 runs.

28 April 2004 (4\% on 30 May), while 9\% (for both dates) of the modelled grid cells are predicted to be snow covered but are snow free within the classification. The model is overestimating the extent of the snow coverage on both dates and over the total area. The modelled snow line lies approximately $200-400 \mathrm{~m}$ in distance lower than the observed one. It has to be stated that an exact analysis of the model error is difficult due to the fact that the snow line is located in wooded regions on both observation dates.

Another compelling result is that predicted snow cover distributions are much more homogeneous when compared to mapped classification results. While independent of the wind fields used (MM5 or interpolated), it can be attributed to an inability of the model to reproduce the extent of the real transport rates and/or to the fact that the model is not able to handle all transport processes relevant, such as e.g. preferential snow distribution or snow slides.

In order to further analyze SnowModel $(30 \mathrm{~m})$ performance, areas which are snow free within the Landsat 7 ETM+ images, but are predicted to be snow covered were detected in a first step. Then, SnowModel results with and without MM5 wind field integration were compared with a SnowModel run omitting wind induced transport. Using this run as basis, it is possible to determine to which extent SnowModel results could be improved by including the blowing snow model algorithm in combination with interpolated wind fields or MM5 wind fields.

In a subsequent step, nine validation areas were selected within a Landsat 7 ETM+ image of April 2004 and six for the May image (Fig. 14a and b). The selection criteria was that respective areas are snow free in the satellite images while being snow covered in the model results. The values shown in Tables 4 and 5 are averages for the named area. Results show that the run without lateral snow transport is overestimating the SWE significantly on 28 April, 2004 and slightly on 30 May, 2004. It is obvious that the inclusion of snow transport processes in combination with interpolated wind fields does not lead to a significant improvement in SnowModel performance, and the accuracy of the results may even decline when using these fields as input information (Table 4: area 7 and 9; Table 5: area 2). The usage of MM5 wind fields on the other hand leads to improvements for all results and at all dates. On 28 April the results were improved by approximately $23 \%$ while results on 30 May were improved $60 \%$ in average when using the MM5 wind fields. 
a)

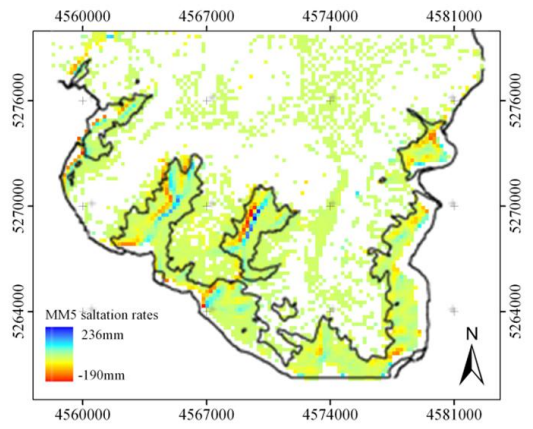

c)

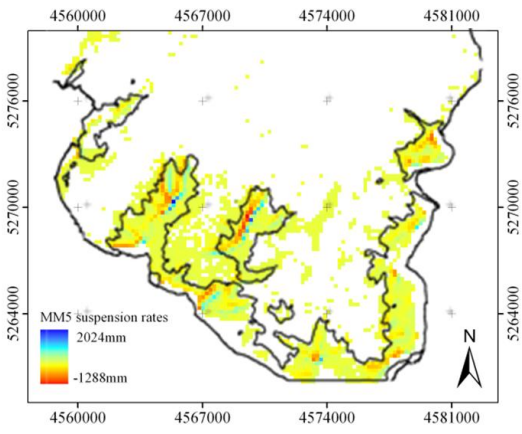

e)

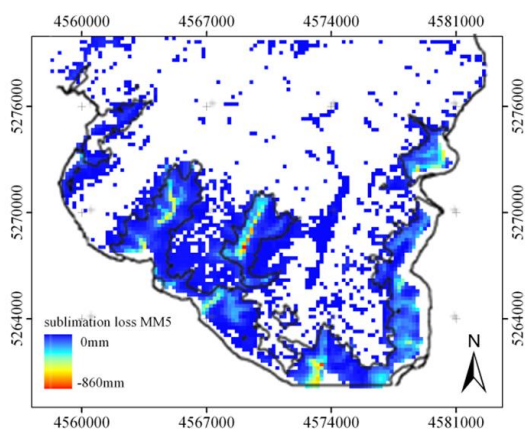

b)

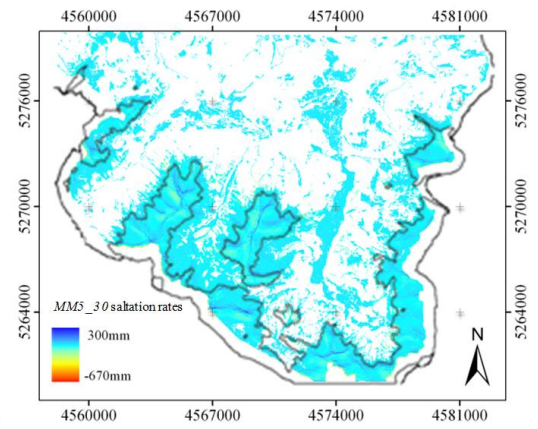

d)

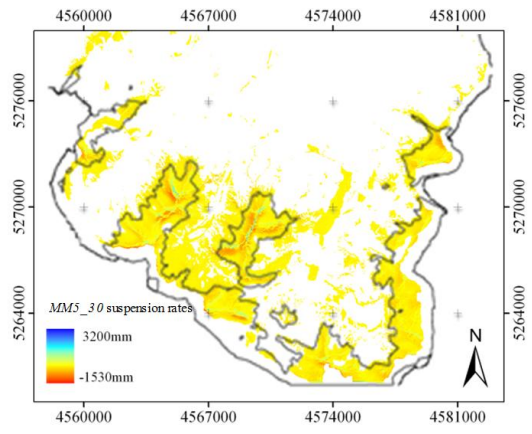

f)

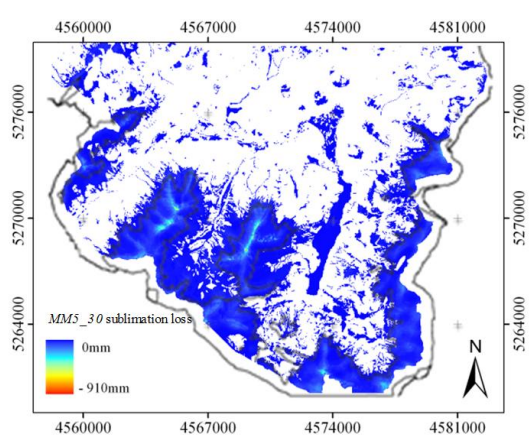

Fig. 12. SnowModel predicted rates of the different transport terms at the $200 \mathrm{~m}$ and at the $30 \mathrm{~m}$ scale (both with SnowModel and MM5): saltation, suspension and sublimation in (a), (c) and (e) for $200 \mathrm{~m}$ model runs, and (b), (d) and (f) for $30 \mathrm{~m}$ model runs with downscaled wind fields. The black line is the $1800 \mathrm{~m}$ isohypsis.

a)

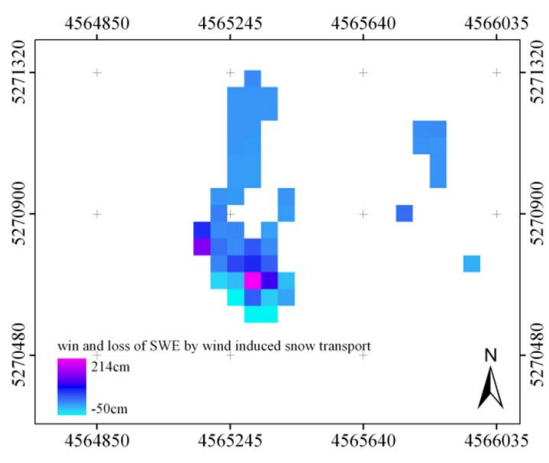

b)

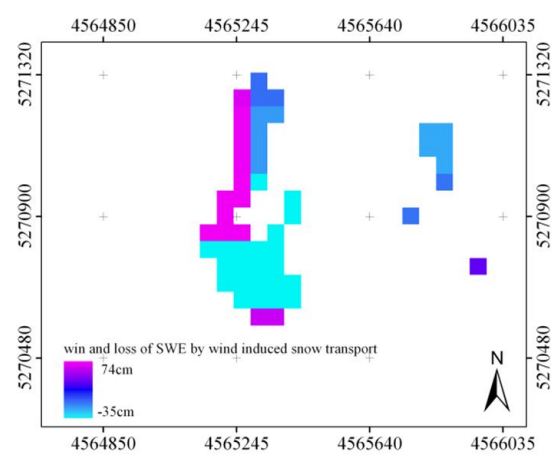

Fig. 13. Predicted loss and gain of SWE due to wind induced snow transport at Blaueis glacier (a) $30 \mathrm{~m}$ resolution results using MM5 wind fields, (b) $200 \mathrm{~m}$ resolution results using MM5 wind fields (the results were fitted to the $30 \mathrm{~m}$ grid for the presentation). 
Table 4. Comparison between SnowModel results generated with SnowTran-3D, with and without the usage of MM5. The values belong to the areas highlighted in Fig. 15a. The areas are snow free in reality, the values within the table showing the improvement of the SnowModel results when the transport routine is used with and without MM5. The percent values standing for the changes of the SWE depth calculated by SnowModel using MM5 or interpolated fields in comparison to SnowModel runs which are omitting snow transport processes.

\begin{tabular}{lrrrrrrrrr}
\hline Improvement when using: & Area 1 & Area 2 & Area 3 & Area 4 & Area 5 & Area 6 & Area 7 & Area 8 & Area 9 \\
\hline Interpolated wind fields & $5 \%$ & $3 \%$ & $3 \%$ & $0 \%$ & $2 \%$ & $2 \%$ & $-100 \%$ & $0 \%$ & $-2 \%$ \\
MM5 wind fields & $28 \%$ & $26 \%$ & $9 \%$ & $16 \%$ & $30 \%$ & $26 \%$ & $12 \%$ & $22 \%$ & $26 \%$ \\
SWE with interpolated wind fields & $-3 \mathrm{~mm}$ & $-2 \mathrm{~mm}$ & $-1 \mathrm{~mm}$ & $0 \mathrm{~mm}$ & $-2 \mathrm{~mm}$ & $-2 \mathrm{~mm}$ & $+132 \mathrm{~mm}$ & $0 \mathrm{~mm}$ & $+2 \mathrm{~mm}$ \\
SWE with MM5 wind fields & $-18 \mathrm{~mm}$ & $-20 \mathrm{~mm}$ & $-3 \mathrm{~mm}$ & $-18 \mathrm{~mm}$ & $-26 \mathrm{~mm}$ & $-23 \mathrm{~mm}$ & $-16 \mathrm{~mm}$ & $-22 \mathrm{~mm}$ & $-21 \mathrm{~mm}$ \\
\hline
\end{tabular}

Table 5. Comparison between SnowModel results generated with SnowTran-3D and with as well as without the usage of MM5. The values belonging to the areas highlighted in Fig. 15b. The areas are snow free in reality, the values within the table showing the improvement of the SnowModel results when the transport routine is used with and without MM5. The percent values standing for the changes of the SWE depth calculated by SnowModel using MM5 or interpolated fields in comparison to SnowModel runs which are omitting snow transport processes.

\begin{tabular}{lrrrrrr}
\hline Improvement when using: & Area 1 & Area 2 & Area 3 & Area 4 & Area 5 & Area 6 \\
\hline Interpolated wind fields & $0 \%$ & -2 & $1 \%$ & $0 \%$ & $1 \%$ & $12 \%$ \\
MM5 wind fields & $80 \%$ & $46 \%$ & $63 \%$ & $55 \%$ & $35 \%$ & $86 \%$ \\
SWE with interpolated wind fields & $0 \mathrm{~mm}$ & $+2 \mathrm{~mm}$ & $-1 \mathrm{~mm}$ & $0 \mathrm{~mm}$ & $-1 \mathrm{~mm}$ & $-2 \mathrm{~mm}$ \\
SWE with MM5 wind fields & $-78 \mathrm{~mm}$ & $-43 \mathrm{~mm}$ & $-39 \mathrm{~mm}$ & $-84 \mathrm{~mm}$ & $-30 \mathrm{~mm}$ & $-31 \mathrm{~mm}$ \\
\hline
\end{tabular}

\section{Summary and discussion}

The downscaling procedure described in 4 was able to improve the convergence between meteorological station and model results in a significant way. The results achieved in Sects. 5.3 and 5.4 are further indicators suggesting the applicability of the presented scheme.

The comparison of field campaign data and model results has shown that SnowModel (with or without MM5) is able to reproduce the measured snow depth at Reiteralm and Kühroint in a satisfying way (c.p. Figs. 6 and 8). Nevertheless, the modelled variability between the different measuring points was still too small (Tables 2 and 3). Transport processes from the higher to the lower part of Reiteralm could not be displayed. Further analysis revealed that this is due to the forest which subdivides Reiteralm into two parts. The model treats this forest as a physical barrier which blocks snow transport. The introduction of an additional vegetation class "sporadic trees" resulted in no improvement. This can be attributed to the general model setup. So, a simple reduction of the snow holding capacity makes more snow available for transport but cannot solve the existing lack within the model formulations. For the appropriate representation of snow transport over the forest land cover, two different wind velocity layers would be required within SnowModel, but only one is currently available. While extending SnowTran$3 \mathrm{D}$ was bey ond the scope of this project, the required input wind fields would in principle be available as from MM5 runs.
The results at Kühroint have demonstrated that SnowModel can reproduce no-transport conditions at a wind sheltered site in combination with downscaled MM5 wind fields. In correspondence to the results at Reiteralm, the overall variance of the modelled data is too small with respect to the snow depth differences between the sample points. This might be due to the DEM used in this study which describes Kühroint, which is undulated in reality, as an almost completely flat area. The DEM at Kühroint was checked because of unexpectedly homogeneous snow distribution within the model results. The analysis revealed some inaccuracies within the data, which were unfortunately detected only after the progression of the field campaign. It became evident that the small knolls in the area are not displayed in the DEM even in its original $10 \mathrm{~m}$ resolution. However, the example shows that the generation of topographical input parameters can be problematic in Alpine regions and can therefore represent a source for deviations between model and measurements.

Wind induced transport of SWE form surrounding areas to Alpine glaciers is mentioned as important for their existence (Kuhn, 1993, 1995). Especially small kar glaciers like the Blaueis glacier (Fig. 10) and many other glaciers e.g. in the Karwendel region (Austria) are dependent on additional SWE delivered by avalanches or wind induced snow transport (Kuhn 1995). Plattner et al. (2006) have applied a statistical analysis of the SWE distribution at Vernagtferner (Tirol/Austria) and have found that the SWE distribution is very likely dependent on the wind conditions and on wind induced snow transport. However, a quantitative estimation 
a)

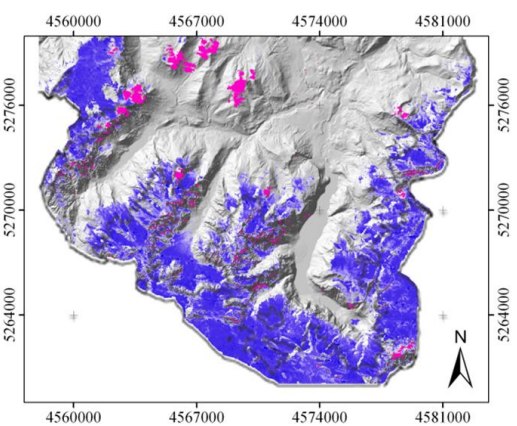

c)

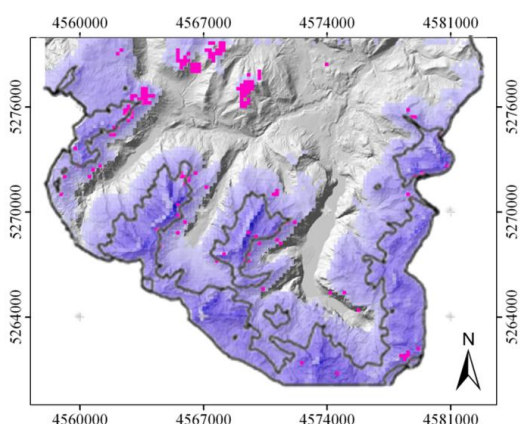

e)

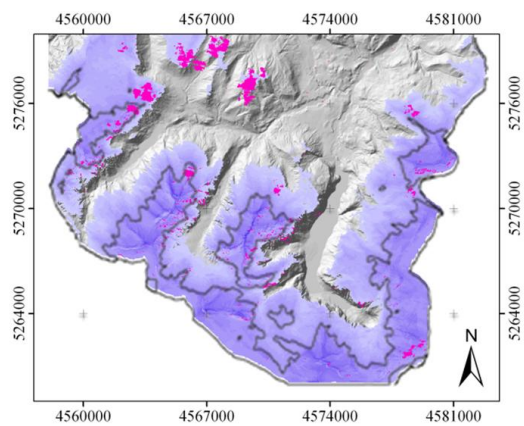

b)

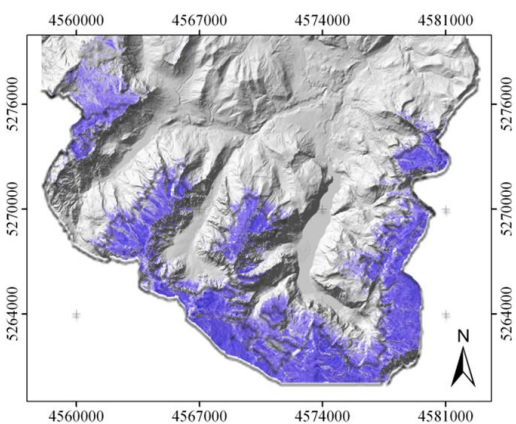

d)

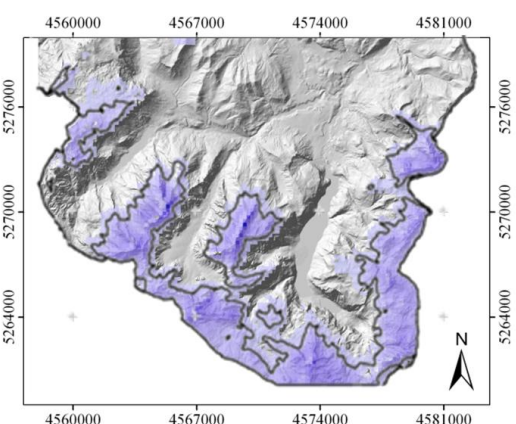

f)

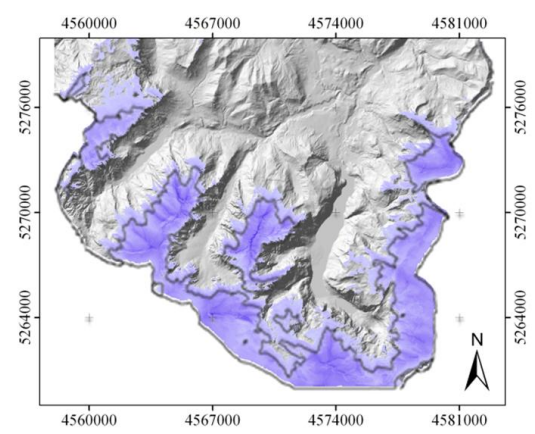

Fig. 14. Comparison between SnowModel derived and Landsat 7 ETM+ NDSI classified snow cover distribution (a) NDSI map of 28 April, 2004; (b) NDSI map of 30 May, (c) Modelled snow cover of 28 April, 2004 (200 m resolution) (d) 30 m resolution, (e) Modelled snow cover of 30 May, 2004 (200 m resolution) (f) $30 \mathrm{~m}$ resolution. The snow cover is indicated with the blue colour, clouds are masked with the pink colour.

a)

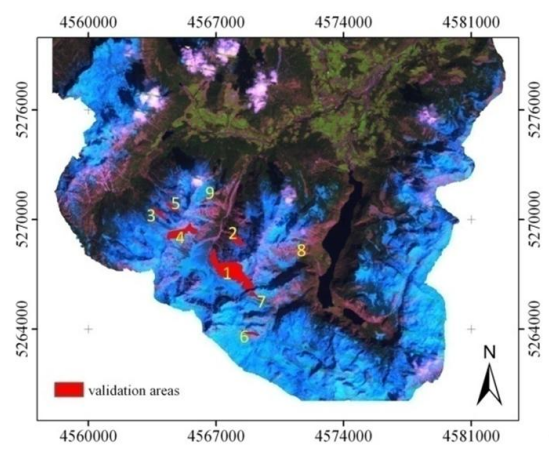

b)

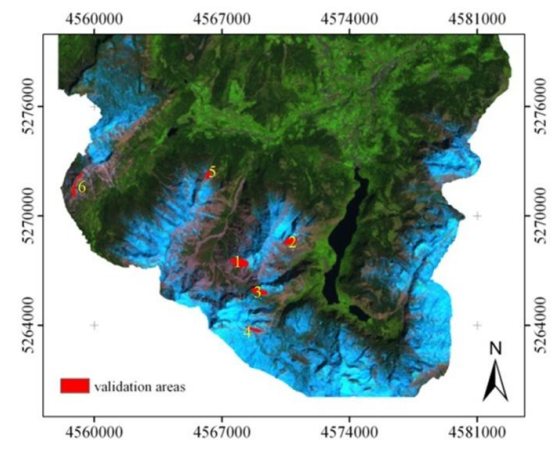

Fig. 15. (a) validation areas of 28 April, 2004: Blue: snow cover, Red: test areas. (Bands: 5,4,3) (b) validation areas of 30 May, 2004 : Blue: snow covered regions, Red: test areas (Bands: 5,4,3). 
of the transported amounts was not possible there. Results presented here indicate that SnowModel-MM5 predictions at the $30 \mathrm{~m}$ scale are well able to account for these transported SWE amounts.

The analysis of the general snow cover distribution within the National Park area (Fig. 8) has shown that the effect of wind induced snow transport on the total snow cover distribution is significant at the $200 \mathrm{~m}$ scale. However, results at the $30 \mathrm{~m}$ scale reveal the importance of wind induced snow transport on spatially limited regions, such as the Blaueis glacier or the crest regions of Hochkalter and Watzmann. The effect on the total snow distribution within the National Park is negligible when using the higher model resolution (Fig. 9). This finding is also true for the calculated sublimation rates. The sublimation loss can reach $910 \mathrm{~mm}$ within a few pixels at the crest regions. Nevertheless, the influence of the sublimation process on the water balance for the total region is small within the $30 \mathrm{~m}$ results. The average loss by sublimation is $0.5 \mathrm{~mm}$ per pixel here which is considerably smaller than the 12 millimetres predicted with the 200 m model resolution (Fig. 11e and f).

While the integration of $30 \mathrm{~m}$ MM5 wind fields can improve SnowModel results in comparison to the satellite images (Tables 4 and 5), SnowModel in combination with interpolated wind fields can also reduce the accuracy of the results (Tables 4 and 5). This indicates that the downscaled MM5 wind fields are more reliable - at least in Alpine settings - than interpolated wind fields which are the standard setting for the application of SnowModel.

The comparison to the remotely sensed data has also shown that the modelled snow cover is too homogeneous with respect to the mapped snow cover. The inclusion of the $30 \mathrm{~m}$ MM5 wind fields has also lead to a more heterogeneous snow distribution and to an improvement of the spatial SWE distribution (Tables 4 and 5). Nevertheless, the inclusion of additional processes like gravitational snow transport or preferential snow deposition would be needed to obtain a more realistic picture of the snow distribution.

As the accuracy of the presented approach is not dependent on the general location of the observed area, it could be a helpful alternative for any Alpine environments, independent on the quality and density of monitoring strategies.

Acknowledgements. The authors want to thank the National Park Berchtesgaden authority for providing the GIS information and the meteorological data, as well as the Bavarian Avalanche Warning Service for meteorological data. A special thank goes to the National Park rangers, who accomplished the snow depth measurements; this encouragement of the rangers cannot be acknowledged high enough because of the prevailing local conditions.

Edited by: M. Van den Broeke

\section{References}

Adrian, G. and Frühwald, D.: Design der Modellkette GME/LM, PROMET, 27, 106-110, 2002.

Balk, B. and Elder K.: Combining binary decision tree and geostatistical methods to estimate snow distribution in a mountain watershed, Water Resour. Res., 36, 13-26, 2000.

Bernhardt, M., Zängl, G., Liston, G. E., Strasser, U., and Mauser, W.: Using wind fields from a high resolution atmospheric model for simulating snow dynamics in mountainous terrain, Hydrol. Process., 23, 1064-1075, 2009.

Blöschl, G. and Sivapalan, M.: Scale Issues in Hydrological Modeling - a Review, Hydrol. Process., 9, 251-290, 1995.

Bowling, L. C., Pomeroy J. W., and Lettenmaier, D. P.: Parameterization of Blowing-Snow Sublimation in a Macroscale Hydrology Model, J. Hydrometeorol., 5, 745-762, 2004.

Bruland, O., Liston, G. E., Vonk, J., Sand, K., and Killingtveit, A.: Modelling the snow distribution at two high arctic sites at Svalbard, Norway, and at an Alpine site in central Norway, Nordic Hydrology, 35, 191-208, 2004.

Déry, S. J. and Yau, M. K.: A Bulk Blowing Snow Model, Bound. Lay. Meteorol., 93(2), 237-251, 1999.

Doesken, N. J and Judson, A.: The Snow Booklet: A guide to the science, climatology, and measurement of snow in the United States, Colorado State University, Fort Collins, CO, 1996.

Doorschot, J.: Mass transport of drifting snow in high alpine environments, online available at: http://e-collection.ethbib.ethz.ch/ show?type $=$ diss $\backslash \& n r=14515,2002$.

Eidsvik, K. J., Holstad, A., Lie, I., and Utnes, T.: A Prediction System for Local Wind Variations in Mountainous Terrain, Bound.Lay. Meteorol., 112(3), 557-586, 2004.

Essery, R. L. H., Li, L., and Pomeroy, J. W.: A Distributed Model of Blowing Snow over Complex Terrain, Hydrol. Process., 13, 2423-2438, 1999.

Essery, R. L. H.: Spatial statistics of windflow and blowing-snow fluxes over complex terrain, Bound.-Lay. Meteorol., 100, 131147, 2001.

Greene, E. M., Liston, G. E., and Pielke, R. A.: Simulation of above treeline snowdrift formation using a numerical snow-transport model, Cold Reg. Sci. Technol., 30, 135-144, 1999.

Grell, G. A., Dudhia, J., and Stauffer, D. R.: A description of the fifth generation Penn State/NCAR mesoscale model (MM5), Technical report, National Centre for Atmospheric Research, Boulder, Colorado, USA, 1995.

Hall, D. K., Riggs, G. A., and Salomonson, V. V.:Development of Methods for Mapping Global Snow Cover Using Moderate Resolution Imaging Spectroradiometer Data, Remote Sens. Environ., 54, 127-140, 1995.

Hasholt, B., Liston, G. E., and Knudsen, N. T.: Snow-distribution modelling in the Ammassalik region, south east Greenland, Nordic Hydrology, 34, 1-16, 2003.

Hiemstra, C. A. A., Liston G. E., and Reiners W. A.: Snow redistribution by wind and interactions with vegetation at upper treeline in the Medicine Bow Mountains, Wyoming, USA, Arctic Antarctic and Alpine Research, 34, 262-273, 2003.

Hiemstra, C. A., Liston, G. E., and Reiners, W. A.: Observing, modelling, and validating snow redistribution by wind in a Wyoming upper treeline landscape, Ecol. Modell., 197, 35-51, 2006.

Kuhn, M: Zwei Gletscher im Karwendelgebirge, Zeitschrift für Glaziologie und Gletscherkunde, 29/1, 85-92, 1993. 
Kuhn, M.: The mass balance of very small glaciers, Zeitschrift für Glaziologie und Gletscherkunde, 31, 171-179, 1995.

Lehning, M., Doorschot, J., Raderschall, N., and Bartelt, P.: Combining snow drift and SNOWPACK models to estimate snow loading in avalanche slopes, Snow Eng., 4, 113-122, 2000.

Lehning, M., Völksch, I., Gustafsson, D., Nguyen, T. A., Stähli, M., and Zappa, M.: ALPINE3D: A detailed model of mountain surface processes and its application to snow hydrology, Hydrol. Process., 20, 2111-2128, 2006.

Liston, G. E.: Local Advection of Momentum, Heat, and Moisture during the Melt of Patchy Snow Covers, J. Appl. Meteorol., 34, 1705-1715, 1995.

Liston, G. E. and Sturm, M.: A snow-transport model for complex terrain, J. Glaciol., 44, 498-516, 1998.

Liston, G. E., Winther, J. G., Bruland, O., Elvehoy, H., Sand, K., and Karlof, L.: Snow and blue-ice distribution patterns on the coastal Antarctic Ice Sheet, Antarctic Science, 12, 69-79, 2000.

Liston, G. E. and Sturm M.: Winter Precipitation Patterns in Arctic Alaska Determined from a Blowing-Snow Model and SnowDepth Observations, J. Hydrometeorol., 3, 646-659, 2002.

Liston, G. E:. Representing Subgrid Snow Cover Heterogeneities in Regional and Global Models, J. Climate, 17, 1381-1397, 2004.

Liston, G. E. and Elder, K.: A distributed snow-evolution modeling system (SnowModel), J. Hydrometeorol., 7, 1259-1276, 2006.

Plattner, C., Braun, L., and Brenning, A.: The spatial variability of snow accumulation at Vernagtferner, Austrian Alps, in Winter 2003/2004, Zeitschrift für Gletscherkunde und Glazialgeologie, 39, 43-57, 2006.
Pomeroy, J. W., Gray, D. M., and Landine, P. G.: The Prairie Blowing Snow Model - characteristics, validation, operation, J. Hydrol., 144, 165-192, 1993.

Pomeroy, J. W., Gray, D. M., Shook, K. R., Toth, B., Essery, R. L. H., Pietroniero, A., and Hedstrom, N.: An evaluation of snow accumulation and ablation for land surface modelling, Hydrol. Process., 12, 2339-2367, 1998.

Prasad, R., Tarboton, D. G., Liston, G. E., Luce, C. H., and Seyfried, M. S.: Testing a blowing snow model against distributed snow measurements at Upper Sheep Creek, Idaho, United States of America, Water Resour. Res., 37, 1341-1356, 2001.

Ryan, B. C.: A mathematical model for diagnosis and prediction of surface winds in mountainous terrain, J. Appl. Meteorol., 16, 571-584, 1977.

Strasser, U., Bernhardt, M., Weber, M., Liston, G. E., and Mauser, W.: Is snow sublimation important in the alpine water balance?, The Cryosphere, 2, 53-66, 2008, http://www.the-cryosphere-discuss.net/2/53/2008/.

Winstral, A. and Marks, D.: Simulating wind fields and snow redistribution using terrain-based parameters to model snow accumulation and melt over a semi-arid mountain catchment, Hydrol. Process., 16, 3585-3603, 2002.

Zängl, G.: An Improved Method for Computing Horizontal Diffusion in a Sigma-Coordinate Model and Its Application to Simulations over Mountainous Topography, Mon. Weather Rev., 130, 1423-1432, 2002.

Zängl, G.: Orographic Gravity Waves Close to the Nonhydrostatic Limit of Vertical Propagation, J. Atmos. Sci., 60, 2045-2063, 2003. 